\title{
REPRESENTAÇÕES DA IDENTIDADE NACIONAL NA CAMPANHA PUBLICITÁRIA KEEP WALKING, BRAZIL
}

\author{
PAULINE NEUTZLING FRAGA \\ UNIVERSIDADE FEDERAL DE SANTA MARIA \\ SANTA MARIA, RIO GRANDE DO SUL, BRASIL \\ E-MAIL: PAULINE_FRAGA@HOTMAIL.COM \\ ADA CRISTINA MACHADO SILVEIRA \\ UNIVERSIDADE FEDERAL DE SANTA MARIA \\ SANTA MARIA, RIO GRANDE DO SUL, BRASIL \\ E-MAIL: ADAC.MACHADOSILVEIRA@GMAIL.COM
}

HTTP://DX.DOI.ORG/10.5902/2316882X25756 


\section{REPRESENTAÇÕES DA IDENTIDADE NACIONAL NA CAMPANHA PUBLICITÁRIA KEEP WALKING, BRAZIL}

Resumo: O artigo ocupa-se da investigação das representações de brasilidade presentes na campanha publicitária Keep walking, Brazil (2011), da marca Johnnie Walker. Como objetivo geral pretendeu-se investigar quais os principais traços da identidade nacional brasileira presentes na campanha e as prováveis relações de poder implícitas, considerando-se as formas simbólicas propostas.

Palavras-chave: Mídia; Representações; Identidade cultural; Narrativa publicitária; Brasilidade.

\section{LAS REPRESENTACIONES DE LA IDENTIDAD NACIONAL EN LA CAMPAÑA DE PUBLICIDAD KEEP WALKING, BRAZIL}

Resumen: El artículo trata de la investigación de las representaciones presentes en la campaña publicitaria Keep Walking, Brazil (2011), de la marca Johnnie Walker. Como objetivo general se pretende investigar cuáles son las principales características de la identidad nacional brasileña presentes en la campaña y las probables relaciones del poder implícitas, considerando las formas simbólicas propuestas.

Palabras clave: Medios de comunicación; Representaciones; Identidad cultural; Narración publicitaria. Brasilidad.

\section{REPRESENTATIONS OF NATIONAL IDENTITY IN THE ADVERTISING}

\section{CAMPAIGN KEEP WALKING, BRAZIL}

Abstract: The article deals with the investigation of the Brazilianness present representations in the hype Keep walking, Brazil (2011), by brand Johnnie Walker. As a general objective was intended to investigate what the main features of Brazilian national identity in the present campaign and the probable relationship of implied power, considering that the symbolic forms proposed.

Keywords: Media; Representations; Cultural Identity; Narrative Advertising; Brasility. 


\section{INTRODUÇÃO}

A pesquisa de doutorado que origina este artigo investigou as relações de poder que sustentam as representações da identidade brasileira presentes na narrativa publicitária da campanha Keep walking, Brazil, voltada exclusivamente aos consumidores brasileiros, assinada pela marca de uísques escocesa Johnnie Walker. O lançamento em rede nacional da principal peça da referida campanha publicitária ocorreu em outubro de 2011, em canais da TV aberta e fechada. Na narrativa Gigante', como foi intitulada esta peça audiovisual, o Brasil é personificado por um gigante rochoso, a formação do Morro do Pão de Açúcar (Rio de Janeiro), que acorda, se ergue do chão e começa a andar. Paralelamente a esta peça, foram lançados no canal da marca no Youtube 65 audiovisuais de entrevistas com personalidades, apresentadas ao público como Gigantes Brasileiros. Entretanto, devido ao limite do número de páginas, a análise apresentada neste artigo focará no audiovisual Gigante e na redação A Lenda do Gigante.

De consumo popularizado há algum tempo no país da cachaça e da caipirinha, o hábito de beber uísque vem conquistando não apenas a simpatia e o paladar dos brasileiros. Nunca na história do Brasil se consumiu tanto uísque e uísques de marcas importadas. Uma das explicações é o aumento do poder aquisitivo da classe média, que passou a sentir-se mais à vontade para investir na compra da bebida, considerada um luxo acessível. O fenômeno ocorrido é "uma troca de categorias motivada pelo aumento do poder aquisitivo", como explicou Cláudio Czarnobai, analista de mercado do Instituto de Pesquisa Nielsen (revista Isto É Dinheiro, 11 maio 2012). Segundo Czarnobai, as únicas categorias de bebidas alcoólicas que haviam crescido em volume de consumo em 2012 eram o vinho, o uísque e a vodca, ao contrário da cerveja, da cachaça e do conhaque, que já eram consideradas menos apreciadas nesta época.

A problemática abordada sustentou-se na premissa de que falar em cultura é falar necessariamente em relações de poder e de domínio, a exemplo do pensamento apresentado por teóricos como Thompson (2011), Ortiz (1994) e Silva (2000). Neste sentido, na busca por se compreender a identidade e a cultura brasileira deve-se considerar um histórico 
de disputas de interesses de diferentes grupos sociais. Em se tratando da realidade sócio-histórica estabelecida no Brasil na época em que a campanha foi lançada, outubro de 2011, ressalta-se a conjuntura extremamente favorável à projeção do Brasil no mundo, especialmente como potência econômica e política. Muito diferente da situação bem menos otimista à imagem internacional do país que se delinearia tempos depois, mais precisamente a partir de junho de 2013, com o início das manifestações populares que tomaram as ruas de várias cidades brasileiras. Deste modo, estabeleceu-se como problema de pesquisa a seguinte questão: considerando-se as características das representações da brasilidade presentes na campanha Keep walking, Brazil, que relações de poder tais representações expressam?

Neste sentido, apresenta-se como hipótese a ideia de que as representações presentes nas narrativas da campanha revelem-se inovadoras e positivas na sua superfície, mas que sob um olhar mais aprofundado mantenham relações resultantes da concepção simplista de um Brasil cuja história teria sido forjada pelos determinismos de meio e raça, por exemplo. Ressalta-se que essa situação não necessariamente impeça tais representações de proporem caracterizações alternativas à brasilidade, as quais extravasem, pelo menos em parte, as clássicas estereotipações do Brasil como "país do futebol”, “do samba”, "do carnaval”, “da caipirinha", "das mulatas", entre outras.

\section{DESENVOLVIMENTO}

Na obra Ideologia e Cultura de Massa, Thompson (2011) apresenta sua teoria social da comunicação de massa. O teórico oferece referencial crítico para a análise dos fatos comunicacionais, a qual inclui desde o contexto histórico onde acontecem esses fatos até os processos de produção, transmissão e recepção das formas simbólicas. Nesta investigação, compreende-se a narrativa publicitária como um fato comunicacional capaz de construir formas simbólicas e propô-las ao seu público-alvo a fim de sensibilizá-lo, convencê-lo, persuadi-lo. As representações da brasilidade propostas na campanha Keep walking, Brazil, são, neste sentido, formas simbólicas que tratam da identidade nacional e que constituem implicações não apenas mercadológicas. Tratando-se de um legítimo exemplo de comunicação massiva, sob contextos sócio-históricos específicos, a Rev.Cad. Comun. Santa Maria, v.21, n.1, art 8, p.176 de 181, jan/abr.2017 
publicidade serve como meio de criação e sustentação das relações de dominação econômica e, sobretudo, cultural.

Thompson (2011) compreende "a análise da ideologia como uma forma específica, ou uma versão, da hermenêutica de profundidade", cuja especificidade consiste no fato de que "várias fases do enfoque da hermenêutica de profundidade são empregadas com o objetivo de realçar o caráter ideológico das formas simbólicas, isto é, com objetivo de realçar as maneiras como o sentido serve para estabelecer e sustentar relações de dominação" (THOMPSON, 2011, p.35).

O referencial metodológico da Hermenêutica de Profundidade (HP) compreende três fases ou procedimentos analíticos: a análise sócio-histórica, a análise formal ou discursiva e a interpretação/reinterpretação das formas simbólicas. A primeira considera as condições sociais e históricas da produção, circulação e recepção das formas simbólicas. Já a análise formal ou discursiva reflete sobre as formas simbólicas internas, portanto, não são considerados os contextos de produção ou circulação. Por fim, a terceira e última fase, a interpretação e reinterpretação, empreendida pelo analista social.

\subsection{O AUDIOVISUAL GIGANTE E O TEXTO A LENDA DO GIGANTE: MODOS DE OPERAÇÃO DA IDEOLOGIA}

Quanto aos modos de operação da ideologia, pode-se considerar que a campanha apresenta sobreposição de estratégias típicas de construção simbólica. A estratégia de legitimação, por exemplo, é recrutada quando a marca apresenta representações de tal forma a tornar justas e dignas de apoio suas intenções de legitimação. A alegoria do país e do seu povo apresentados como gigantes, neste sentido, parece alcançar dignidade suficiente para ser aceita como verdade e apoiada pelos consumidores. Como subcategoria da legitimação, a estratégia de narrativização da lenda do gigante adormecido. Já a dissimulação, é observada por meio do deslocamento. Neste caso, a expressão "gigante adormecido" é retomada para nomear aqueles indivíduos cujas estórias de vida vitoriosas Ihes permitem serem denominados gigantes brasileiros. Por esta mesma lógica age a estratégia de eufemização: o gigante adormecido, originalmente, se referia à ideia de um país "parado no tempo", ou seja, com potencial para crescer, mas sem proatividade. A eufemização resignifica,

Rev.Cad. Comun. Santa Maria, v.21, n.1, art 8, p.177 de 181, jan/abr.2017 
sugerindo que "antes tarde [acordado] do que nunca".

Por fim, ainda quanto à estratégia de dissimulação, há presença do efeito tropo, observável por meio do uso figurativo da linguagem - a metáfora do gigante para se falar da nação. O tropo constitui-se como uma técnica para dissimular relações de dominação. Um terceiro modus operandi da ideologia também tem sua aplicação observável, a unificação. Como explica Thompson (2011, p.86), relações de dominação podem ser estabelecidas e sustentadas por meio da articulação, em nível simbólico, "de uma forma de unidade que interliga os indivíduos numa identidade coletiva, independentemente das diferenças e divisões que possam separá-los".

\section{CONSIDERAÇÕES}

Silva (2000) explica que a concepção do "ser brasileiro não pode compreendida fora de um processo de produção simbólica e discursiva, no qual esse ser brasileiro não tem nenhum referente natural ou fixo, não é um absoluto que exista anteriormente à linguagem e fora dela" (SILVA, 2000, p.80). Portanto, investigar as representações da nacionalidade na narrativa publicitária, por exemplo, contribui à compreensão das sistemáticas de produção de conteúdo que trabalham a favor das relações de poder: "formular uma identidade nacional, desenhar um perfil de cidadão, estereotipar o caráter de um povo correspondem a práticas que envolvem relações de poder e que objetivam construir mecanismos de coesão social" (LEENHARDT; PESAVENTO, 1998, p.20).

Aquele que tem o poder de representar, tem o poder de definir e determinar a identidade, e é justamente por esse motivo que "a identidade e a diferença não são, nunca, inocentes" (SILVA, 2000, p.81), pois guardam, como qualquer discurso o faz, uma ideologia permeante. Hall (1997), por sua vez, lembra a ideia das culturas nacionais como comunidades imaginadas, problematizando o conceito de nação como uma entidade política que produz sentidos, ou seja, um sistema de representação cultural - uma comunidade simbólica: "uma cultura nacional é um discurso - modo de construir sentidos que influencia e organiza tanto nossas ações quanto a concepção que temos de nós mesmos" (HALL, 1997, p.55). Numa ideia aproximada, Bauman (2005) esclarece que pelo viés do modelo cívico da nacionalidade, a identidade nacional é puramente política; já pela versão étnica, a identidade nacional é puramente cul-

Rev.Cad. Comun. Santa Maria, v.21, n.1, art 8, p.178 de 181, jan/abr.2017 
tural. Mas em ambos os casos, ela se impõe aos indivíduos - não é uma questão de escolha.

Na campanha Keep walking, Brazil persistem resquícios de representações de um ponto de vista colonialista: a ideia de um Brasil que ainda não "ganhou o mundo", portanto, ainda não é vitorioso. Pode-se verificar o entendimento de que o mundo é o mundo exterior ao Brasil, uma condição excludente de pertencimento ao mundo pelo país. Tais representações reforçariam a ideia de que o Brasil ainda estaria deslocado de um reconhecimento internacional e que este poderia ser alcançado a partir de um simbólico primeiro passo. Afinal, no audiovisual o gigante caminha em direção ao Oceano Atlântico, em sentido oposto ao continente, para fora do país, para fora do seu berço cultural.

Durante séculos, as representações acerca do Brasil parecem terem sido dominadas pela cultura hegemônica (no passado) de um país "parado no tempo". Estes pontos de vista propunham e têm proposto que grandeza do país era atrelada especialmente aos seus recursos naturais e humanos (a simpatia e amabilidade do povo, sua receptividade aos turistas, a riqueza das tradições, da sua arte, da música, dos seus desportistas, o talento criativo para inovar e superar adversidades econômicas, etc.), e não necessariamente a boa condução da sua economia, das suas políticas interna e externa, deixando a desejar quanto a um eficiente projeto nacional de desenvolvimento. Exemplos deste olhar seriam trechos na redação publicitária que destacam a riqueza dos recursos naturais e características geográficas brasileiras, as quais funcionam como releituras de uma concepção ainda bastante simplista do Brasil. 


\section{REFERÊNCIAS}

Bauman, Z. (2005). Identidade: entrevista a Benedetto Vecchi. Rio de Janeiro: Zahar.

Hall, S. (1997). A identidade cultural na pós-modernidade. Rio de Janeiro: DP\&A.

SILVA, T. T. da. (2000). A produção social da identidade e da diferença. In: SILVA, T. T. da (org). Identidade e diferença. Petrópolis: Vozes.

Thompson, J.B. (2011). Ideologia e cultura moderna. Teoria social crítica na era dos meios de comunicação de massa. Petrópolis: Vozes.

Woodward, K. (2000). Identidade e diferença: uma introdução teórica e conceitual. In: SILVA, T. T. da (org). Identidade e diferença: a perspectiva dos Estudos Culturais. 4 ed. Petrópolis: Vozes. 


\section{Pauline Neutzling Fraga}

Doutora e mestre pelo Programa de Pós-graduação em Comunicação Midiática da Universidade Federal de Santa Maria (UFSM). Professora do Curso de Publicidade e Propaganda do Centro Universitário Franciscano (Unifra). E-mail: pauline_fraga@hotmail.com

\section{Ada Cristina Machado Silveira}

Doctorado en Periodismo pela Universitat Autònoma de Barcelona (2000). Estágio pós-doutoral na Sorbonne III (França) e na Universidad Nacional de Quilmes (Argentina). Professor Associado IV da Universidade Federal de Santa Maria (UFSM) e Pesquisador do CNPq (Pq2).

E-mail: adac.machadosilveira@gmail.com

A dissertação que originou este artigo foi orientada pela profa. Ada Cristina Machado da Silveira e defendida em 20/10/2016, na linha "Mídias e identidades contemporâneas" do POSCOM-UFSM.

RECEBIDO EM: 01/02/2017

ACEITO PARA PUBLICAÇÃO: 01/04/2017 